\title{
Más allá de la sociología Sobre catástrofes, expertos y comunidades
}

\author{
José Ángel Bergua Amores \\ Universidad de Zaragoza
}

Resumen. El catastrofismo forma parte de una situación estable en la que el saber del analista tiene una relación directamente proporcional con la alienación de los actores. Los economistas saben que situaciones tan inestables como las de pánico dan lugar a fenómenos opuestos: el analista no sabe muy bien lo que pasa, pero el actor sabe desenvolverse bastante bien. Si el mercado, además del funcionamiento estable, admite la inestabilidad, quizás la evitación de catástrofes, además de la solución catastrofista, admita otra inestable, similar al pánico. Llegados a este punto, propondré algunos conceptos que permitan pensar lo inestable y anticatastrofista. Se trata de nociones que dan protagonismo al emergentismo, la autonomía y la incertidumbre. Estas aproximaciones nos llevarán a la frontera donde la sociedad se codea con lo imposible, su afuera. Acerca de ese no ser, el único hacer y el único saber posibles son los que proporciona la sociosofía.

Palabras clave: 1. profecías, 2. autopoiesis, 3. constructivismo, 4. sociosofía.

Abstract. The catastrophic discourse takes part in a stable situation in which the analyst knowledge is directly proportional to the actor alienation. Economist knows that unstable situations like panic produce an opposite phenomenon: the analyst does not know very well what is going on but the actor knows how to manage. If the market, as well as a stable operation, permits instability, the prevention of catastrophes could admit an instable one, similar to panic and together with the catastrophic solution. This paper suggests some concepts to think about this unstable and ant-catastrophic situation. They are notions which give prominence to "emergentism", the autopoiesis and uncertainty. The reinterpretation of hobbesian natural state developed by Foucault, the analysis of the mobilization power of fear made by Bataille and the unpolitical reflections of the community which have been proposed by Esposito, Nancy and Agamben, will be reinterpreted in order to achieve this goalt.

Keywords: 1. Prophecies, 2. autopoiesis, 3. constructivism, 4. sociosophy.

\section{culturates}

VOL. V, NÚM. 9, ENERO-JUNIO DE 2009

ISSN 1870-1191 


\section{Culturales}

\section{El discurso catastrofista}

Dice Dupuy (2002:102-103) Que conviene distinguir las situaciones de riesgo de las situaciones inciertas. Las primeras tienen que ver con acontecimientos que se producen más de una vez y con cierta regularidad, como pasa con las gripes de todos los años. $\mathrm{Su}$ ocurrencia se puede prever en términos probabilísticos y la política que cabe aplicar con base en esa información es la prevención. En cambio, las situaciones inciertas tienen que ver con acontecimientos que sólo se dan una vez y que, por lo tanto, tienen frecuencias inobservables, como ocurre con el peligro de una guerra nuclear o con los efectos del calentamiento global. En este caso la única política posible es la que inspira el principio de precaución. Dicho principio aparece formulado en el punto 15 de la Declaración de Río de Janeiro de 1992. En Europa se introdujo con el Tratado de Maastricht de 1992 y en Francia forma parte del ordenamiento jurídico desde la Ley Barnier, de 1995. Literalmente, dice lo siguiente: "cuando haya peligro de daño grave o irreversible, la falta de certeza científica absoluta no deberá utilizarse como razón para postergar la adopción de medidas eficaces en función de los costos para impedir la degradación del medio ambiente". ${ }^{1}$

Al margen de la delatadora referencia a los costos, conviene subrayar el papel que juega la incertidumbre en las situacio-

${ }^{1}$ Obsérvese cómo el principio parte de una alianza implícita, dada por supuesta, entre la política y la ciencia, en el sentido de que parece que debe ser esta última la que fije la actuación de la primera o le dé cierto auxilio. Sin embargo, el texto afirma explícitamente algo más; sugiere que la falta de certeza científica no deberá impedir la toma de decisiones políticas. Dicho de otro modo, aunque la ciencia deba guiar la acción política, la "falta de certeza científica", en lugar de paralizar la acción política, debe liberarla. Esto da a entender que la lógica de la acción política es superior a la lógica de la verdad científica. Dando un paso más, podemos suponer que la ciencia sólo es el pretexto o la coartada de la acción política. Dicho de otro modo, las verdades científicas están en función de las decisiones políticas. En fin, que lo social se va haciendo a través de decisiones políticas que posteriormente son legitimadas (o no) por reflexiones científicas. 
nes inciertas. Si bien los fenómenos de riesgo y los inciertos tienen ambos que ver con la falta de información, en el caso de los riesgos esa falta de información es objetiva u objetivable (aunque sea en términos "blandos" o probabilísticos), mientras que en los eventos de ocurrencia incierta la falta de información es subjetiva. En efecto, en este segundo caso no hay una realidad exterior a la que se pueda acudir para asegurar que lo que se teme vaya a ocurrir (Dupuy, 2002:132-136). La pregunta es inevitable: si no hay ningún indicio externo, ¿por qué se presume que va a ocurrir algo? Según Dupuy, es la propia precaución la que crea la exterioridad, el peligro incierto.

Obsérvese que hemos llegado más allá de las profecías que se cumplen a sí mismas (Merton, 1987:505 y ss). En efecto, no sucede exactamente que el peligro existe porque lo hace aparecer la precaución. Puesto que lo hace aparecer no como algo seguro o probable sino como algo incierto, la política de la precaución inventa un peligro a la vez que lo conjura. Estamos, pues, ante una profecía que se niega a sí misma. ${ }^{2}$ Esta clase de profecías dan lugar a un orden u organización social que tiene como eje o pilar central los peligros inciertos. Su discurso es el catastrofismo (Gil Calvo, 2003:207 y ss).

Afirma Dupuy que en la actualidad las catástrofes, aunque se hable mucho de ellas, no son creíbles. Lo que quiere decir es que no inducen los cambios de actitud necesarios para que no tengan lugar. Por eso propone inscribir la catástrofe en el futuro de un modo más radical: "hay que volverla ineluctable" (2002:164). $\mathrm{Y}$ hay que hacerlo para que no se cumpla.

${ }^{2}$ Lamo de Espinosa (1990:132-163) se refiere a ellas cuando analiza las interferencias que se producen entre la "reflexividad" de la ingeniería social y la "reflexividad inmediata" que se produce en la vida cotidiana utilizando la información producida por la reflexividad anterior. Los resultados de la interferencia son sorprendentes: "muchas de las más relevantes predicciones en ciencia social han fallado por su éxito práctico: han llegado a conocimiento de los actores cuya conducta se predecía; han sido aceptadas y creídas por ellos; finalmente han orientado y alterado su acción" (1990:138). 


\section{Culturales}

\section{Situaciones estables y alienación}

¿Cómo volver la catástrofe ineluctable? Dupuy sugiere inspirarse en el funcionamiento del mercado. ${ }^{3}$ Allí los agentes económicos interactúan (compran y venden) tomando los precios que con sus actuaciones contribuyen a fijar como si fueran datos fijos, independientes de la acción de los agentes. Dicho de otro modo, los agentes "no saben" que son ellos quienes construyen la realidad, en este caso la de los precios. En cambio, quien sabe que los precios son construidos por los agentes es un observador exterior, el analista. Por lo tanto, el saber del analista y el saber del agente son inversamente proporcionales.

Este escenario, en el que los agentes construyen una realidad gracias a que creen que esa realidad ya está construida, es una típica profecía que se cumple a sí misma. En ella los agentes anticipan un futuro que no saben que contribuyen a producir. Sin embargo, el catastrofismo ya hemos mostrado que da lugar a una situación distinta. Forma parte de una profecía que se niega a sí misma. En este caso, el acontecimiento indeseable que se prevé, aunque sea posible, no se realizará. Es lo que pasa con la disuasión nuclear. La anticipación de la catástrofe no tiene como correlato que se produzca la catástrofe. Sucede justamente lo contrario: la enunciación de la profecía provoca que no se cumpla. ${ }^{4}$ Quizás con la amenaza del calentamiento global que nos lanzan $\mathrm{Al}$ Gore y sus incondicionales suceda algo parecido.

Pues bien, del mismo modo que ocurre en el mercado, lo que hace que el mecanismo "catastrofista" funcione tan bien es que los agentes sociales intervinientes "no saben". En el mercado los actores no saben que producen los precios; en el catastrofismo los actores no saben que van a hacer que la catástrofe no se produzca. Pero en los dos casos, además de que "no sepan" que

${ }^{3}$ En este punto, la reflexión de Neyrat (2006), menos interesada por la lógica liberal, se separa de la propuesta de Dupuy.

${ }^{4}$ Acerca de los juegos que trabajan en el ámbito de las relaciones internacionales y las profecías que se niegan a sí mismas, véase Poundstone (1995:292 y ss). 


\section{Más allá de la sociología}

son ellos los que producen la realidad, es necesario que crean en el carácter objetivo y exterior de la realidad. En concreto, es necesario que en el mercado los agentes crean que los precios tienen vida propia. En el caso del catastrofismo es necesario que se crea que la catástrofe, se haga lo que se haga, aparecerá. Éste es el escenario que plantea Dupuy para volver la catástrofe ineluctable.

El problema es que los agentes que impiden que la catástrofe se produzca no saben lo que hacen. Quien sabe todo (que los agentes no saben, que sus creencias falsas son necesarias y que la realidad no es real sino inventada) es el analista u observador externo. Sólo él puede darse cuenta de que los precios son creados por los actores y que la catástrofe sólo está en las mentes de la gente.

Por lo tanto, aunque este escenario permita conjurar la aparición de la catástrofe, tiene el grave problema de que exige la alienación de la gente. Por ello es necesario buscar un escenario distinto en el que tal alienación no sea imprescindible. No estamos, pues, de acuerdo con la ineluctabilidad de Dupuy.

\section{Desalienación e inestabilidad}

Ese escenario distinto, tanto para el mercado como para las catástrofes, es aquel en el que los analistas no saben qué ocurre y, en cambio, los actores demuestran "saber" desenvolverse bastante bien. Sucede en las situaciones metaestables, bien distintas a las estables que hemos tenido en cuenta hasta ahora. Por ejemplo, en los momentos de pánico financiero, sin precios estables, los actores sobreviven imitándose mutuamente y los analistas no saben analizar ese desenfreno mimético. Por lo tanto, cuando el mercado se vuelve inestable, los agentes saben y los analistas u observadores no saben. Dicho de otro modo, la desalienación de los actores trae consigo un no saber en los analistas (Orlean, 1992:113-143). 


\section{Culturales}

Según los especialistas, el mundo financiero funciona más cerca de esta situación inestable e impredecible que del viejo equilibrio smithiano. En este escenario el analista debiera ser más modesto, reconocer que no sabe y que su no saber es un buen indicador de la autonomía y desalienación de los agentes colectivos. ${ }^{5} \mathrm{O}$ sea que cuanto menos sepa el analista mejor le irá a lo social.

En el caso de las catástrofes hay que proponer un escenario similar al del pánico financiero. Un escenario en el que los actores todavía puedan actuar a pesar de no haber prognosis de catástrofes Si en la situación estable que nos planteaba Dupuy los analistas sabían que la mejor manera de evitar las catástrofes era que se creyera que iban a ocurrir, en las situaciones inestables, donde desaparece el miedo a las catástrofes, los analistas comprobarían que el sistema seguiría funcionando normalmente, sin provocar la catástrofe real... ¡ a pesar de que ya no se cree en ella! Los analistas, en fin, comprobarían que se seguiría evitando la catástrofe pero sin saber exactamente por qué ni cómo.

Con un poco de sosiego, los aturdidos analistas podrían reconocer que el mundo puede funcionar perfectamente sin la prognosis de catástrofes. El problema es que resulta muy difícil pensar ese otro modo de ser del mundo. Para hacerlo hay que ir más allá de la modernidad.

\section{4. ¿El hombre es un lobo para el hombre?}

Las situaciones estables que gravitan en torno al miedo a una catástrofe no son ni mucho menos excepcionales. En realidad, reproducen formal y sustancialmente la situación que dio lugar al nacimiento del Estado moderno.

${ }^{5}$ A una conclusión idéntica ha ido a parar Rosset (2004:176-183). En su opinión, el pánico tiene lugar cuando lo real (lo insignificante que precede y excede nuestras re-presentaciones) se le aparece súbitamente al espíritu sin darle tiempo para reflexionar, sin darle la posibilidad de rehacer las cosas. 


\section{Más allá de la sociología}

En el plano formal, el contrato hobbesiano sustituye relaciones interindividuales de carácter horizontal por relaciones verticales que convergen en un punto fijo exógeno, puesto a distancia de los individuos. Ese punto trascendente es el Estado. Y su existencia es muy similar a la de los precios y las catástrofes en las situaciones estables. En todos los casos es necesario que los agentes no sepan que dan vida a esas realidades que se creen exteriores. En cambio, el analista sí que tiene conocimiento de ello.

Por lo que respecta al contenido, el argumento de Hobbes es conocido: el miedo y el terror que inspira el otro es eliminado haciendo que sea el Estado quien los provoque. En esto consiste la paz hobbesiana, en que el terror sea reorientado. Espósito (2003:43) ha señalado la paradoja que este contrato instaura: los individuos pasan a vivir de la renuncia a con-vivir, "la vida es conservada propiciando su sacrificio". De todas formas, para nuestro propósito, más importante que la paradoja es la constatación de que, según Hobbes, como sucede en el mercado, antes del Estado hay una situación inestable, sin puntos fijos trascendidos. En esta situación prepolítica el miedo circula libre y anárquicamente por lo social. Según las interpretaciones al uso, esta situación en la que el "hombre es un lobo para el hombre" es poco menos que insufrible. Sin embargo, Foucault (1992:99-101) asegura que este estado de pánico no debe ser interpretado en términos tan apocalípticos; simplemente, da lugar a un distinto modo de regulación de la violencia y del miedo.

En efecto, "la guerra primitiva, la guerra de todos contra todos -dice Foucault- es una guerra determinada por la igualdad, nacida de la igualdad y que se desarrolla dentro de esa igualdad". Ese estado original de rivalidad entre iguales da lugar a una paz social muy distinta a la que tutela el Estado. En concreto, Foucault entiende que se garantiza con base en tres series de elementos. Primero, "yo me represento la fuerza del otro, me represento el hecho de que el otro se representa mi fuerza, y así sucesivamente". Segundo, "se hace ver que se quiere la guerra, se hace ver la intención de no renunciar a ella". Y tercero, "temo 


\section{Culturales}

tanto hacer la guerra que estaré tranquilo sólo si tú llegas también a temerla por lo menos tanto como yo y en lo posible un poco más". De modo que en el Estado de Guerra Primitiva de Hobbes no hay armas ni fuerzas salvajes sino un Teatro que se encarga de contener el peligro de la violencia dramatizándola, jugando a hacerse miedo. ${ }^{6}$

En definitiva, si en las situaciones estables, tuteladas por el Estado, el tipo de regulación es alopoiético (deriva de un punto fijo exógeno, el Estado), en las situaciones inestables, dominadas por las relaciones interindividuales, la regulación es autopoiética (emana de un punto fijo endógeno, la totalidad interindividual). ${ }^{7}$

La posición del participante es en ambas situaciones diferente. En la primera no sabe que da vida a ese Estado que cree que es el único garante de la seguridad, mientras que en el teatro prepolítico

${ }^{6}$ En otro lugar he interpretado algunas de las violencias juveniles, que tanto temen nuestras ordenadísimas sociedades, a partir de la idea de juego (Bergua, 2002:91 y ss). Por otro lado, con relación a la violencia no conviene olvidar a Clastres. En su opinión, una de las funciones que cumplen en las guerras a las que son tan aficionados los yanomami (que viven entre Venezuela y Brasil) es la de inducir cierto grado de inestabilidad social que bloquee la emergencia de cualquier metanosotros político. Y es que el Estado sólo es posible en un entorno de paz generalizada (Clastres, 1981:184). Por eso Deleuze y Guattari (1988:365) entendieron que la guerra, la "máquina de guerra", es exterior al Estado. Más aún, "la guerra es el mecanismo más seguro para impedir la formación del Estado". Finalmente, conviene tener en cuenta a Benayag y Del Rey (2007:157 y ss): las guerras totales contemporáneas que buscan la aniquilación del contrario son el resultado inevitable de un deseo de paz total; las guerras antiguas y primitivas son menos destructivas porque reconocen que la discordia y el conflicto están en la base del mundo.

${ }^{7}$ Acerca de las diferencias entre autopoiesis y alopoiesis, véase Maturana y Varela (1994:71). Por otro lado, la situación alopoiética tiene que ver con la "hegemonía" de Laclau (2005). Dicha hegemonía depende del establecimiento de relaciones de equivalencia entre elementos a través de puntos fijos exógenos que él denomina "significantes vacíos". Por su parte, la situación autopoiética tiene que ver con la heterogeneidad constitutiva que precede a los puntos fijos exógenos, a las relaciones de equivalencia e incluso a las mismas diferencias entre elementos (2005:9597 y $78-88)$. 
tiene control sobre su vida y contribuye a crear un orden distinto, autopoiético. El analista, por su parte, tiene un saber o conocimiento de lo que sucede en ambas situaciones que es exactamente inverso al de los participantes. En la situación estable sabe que el Estado es una ficción y que su existencia depende de la fe y colaboración de los individuos. En cambio, en la situación inestable, aunque pueda percibir ese teatro de fuerzas que menciona Foucault, no sabe explicar cómo se genera el orden.

\section{5. ...y el miedo os hará libres}

El problema es que muchos analistas que se enfrentan a situaciones inestables no saben que no saben. Les pasa eso cuando utilizan explicaciones basadas en la existencia de puntos fijos exógenos. Como tales explicaciones sólo valen para las situaciones estables, la inestabilidad quedará sin explicar. En esos casos el analista no sabe que no sabe.

Esto es precisamente lo que ocurre con Beck (1991 y 1993). En su opinión, ante las catástrofes, el vínculo interindividual que suele emerger se alimenta de distopías o utopías negativas. Esto quiere decir que no desaparecen los metarrelatos o ideologías; simplemente cambian de signo. Pasan de recrear paraísos a evocar infiernos. Ese cambio, en realidad, no es tal, pues tanto los paraísos como los infiernos son puntos fijos exógenos que inspiran la vida colectiva. Y de lo que se trata es de explicar la inestabilidad sin esos apoyos externos.

Ésta fue precisamente la apuesta de Bataille (1993:3-7). Su reconocimiento de que las situaciones inestables exigían explicaciones endógenas le llevaron a reconocer que en tales situaciones el saber experto no valía. En efecto, dicho con sus propias palabras, cualquier colectivo adquiere vocación rupturista, y por lo tanto dice "no" expresa o implícitamente al orden instituido, a partir de la experiencia afectiva de una conciencia desgarrada por la certidumbre $o$ experiencia de la muerte, el sufrimiento, la privación, la imposición, 


\section{Culturales}

etcétera, presentes. Pues bien, añade Bataille que en esa situación (inestable) "el porvenir no descansa sobre los minúsculos esfuerzos de algunos agrupadores dotados de un optimismo incorregible, pues depende de la desorientación general" (1993:6).

Obsérvese cómo esta explicación es endógena, mientras que la de Beck introducía puntos fijos exógenos (las distopías o utopías negativas). Por otro lado, al desautorizar a los líderes Bataille está cuestionando el punto de vista experto. En tercer lugar, reconociendo la importancia de la desorientación general está asumiendo que no sabe explicar lo que ocurre en la inestabilidad. En definitiva, a diferencia de lo que sucede con las explicaciones clásicas, como la de Beck, Bataille sabe que no sabe.

\section{La comunidad "no es"}

Es el momento de dar un paso decisivo. Todas las reflexiones anteriores nos han encaminado a la inestabilidad y al protagonismo que tiene en ella lo interindividual. Podemos añadir ahora que lo interindividual, por su carácter prepolítico, tiene que ver con la noción de "comunidad", muy presente desde sus orígenes en el pensamiento político y sociológico moderno. Sin embargo, a pesar de ocupar un lugar central en la reflexión, resulta desconocida para el analista. Lo prueba el hecho de que las explicaciones clásicas y contemporáneas oscilan entre exagerados optimismos y exacerbados pesimismos. Los primeros para recrear las bases míticas adjudicadas al Pueblo que debe tutelar el Estado; los segundos para sustituir ese pueblo, que nunca está a la altura de lo que se espera de él, por parlamentos, partidos políticos, sindicatos, movimientos sociales, etcétera. En fin, que la comunidad siempre ha sido pensada a partir de distintas clases de puntos fijos exógenos.

Jean-Luc Nancy (2000) escribió, en el prólogo para la edición en castellano de La comunidad inoperante, que después del exterminio nazi, realizado precisamente en el nombre de la co- 
munidad, se cerró la posibilidad de pensar cualquier "ser" de la comunidad (por ejemplo, el linaje, la sangre, la lengua, etcétera), pero se alumbró la tarea de pensar el estar-en-común. En mi opinión, la posibilidad de pensar un "ser" para la comunidad no debe cerrarse en absoluto. Sólo exige un pensamiento más sutil y refinado. Por ejemplo, el que estimula la noción de imaginario. ${ }^{8}$ De todas formas, mi intención en lo que sigue es hacer caso a la sugerencia de Nancy y pensar la comunidad no en términos ontológicos (o de "ser") sino en términos de "estar".

Este "estar" puede ser captado si atendemos a la etimología de "comunidad". Dice Espósito (2005:14-16) que el término deriva del latín munus, que significa carga o deuda que debe intercambiarse entre individuos. Munus, a su vez, deriva de la raíz indoeuropea mei-, que significa "cambiar", "mover", "ir", y está relacionado con términos que aluden al intercambio de bienes y servicios (Roberts y Pastor, 1997:103-104). Si lo propio de la comunidad es la circulación de cierto munus, y dicho munus, a su vez, implica cambio y movimiento, resulta que la comunidad tiene que ver con un intenso y excitado estado de contagio o propagación. Y esto porque lo importante no son los sujetos, bienes o signos que se puedan intercambiar (y que remiten al ser u ontología que Nancy propone evitar), sino el hecho de intercambiarlos, de moverlos y de moverse entre y con ellos. Esa propagación supera cualquier límite y, en consecuencia, "interrumpe" (Nancy, 2000:107) cualquier comunidad instituida. Sin embargo, esa interrupción no crea nada nuevo; más bien impulsa el regreso a su inmanencia, al puro movimiento y contagio. Lo propio de la comunidad es, pues, morir en esa inmanencia. De ahí su carácter "inoperante".

García Calvo ha hablado del "pueblo" de un modo parecido.

${ }^{8}$ Véase, por ejemplo, el magnífico trabajo de Carretero Pasín (2006) sobre la eficacia de lo imaginario en el campo de la ideología.

${ }^{9}$ Agustín García Calvo pertenece a una interesante tradición de las letras castellanas que no tiene parangón en el resto de Europa (quizás la excepción sea Rabelais), pues ha puesto al pueblo en el centro de su reflexión y figuración. Dos ejemplos de este interés son las conocidas reflexiones de Juan de 


\section{Culturales}

En cierta ocasión llamó la atención sobre el hecho de que la voz latina para nombrarlo (populus) tiene una gran proximidad onomatopéyica con la voz utilizada para designar al álamo (poopulus) -llamado tremolera en castellano, tremoleta en aragonés-, y explotó esta relación para sugerir que el pueblo o la gente, como el álamo, es trémulo, vaivén, movimiento incesante (García Calvo, 1999). La ocurrencia puede ser comprendida mejor si observamos la lengua cuando es hablada, el campo preferido por García Calvo para tratar del pueblo. En ese hablar sucede que los deícticos y otros índices mostrativos, como 'yo', aquí', 'ahora' (que tienen la particularidad de producir sentido no apelando a significados ya establecidos sino al propio proceso de enunciación), no cesan de moverse y de señalar sujetos, lugares y tiempos distintos (García Calvo, 1993:91-117). Pues bien, "es la perpetua disponibilidad del "yo" (o de cualquier otro índice) para mudar de sitio o estar en cualquier lugar lo que permite tener a tal índice una inestabilidad similar a las de las partículas elementales". Esta parte de la lengua -añade García Calvo- pertenece al pueblo y no tiene nada que ver con las gramáticas y palabras con significado que vigilan los expertos, especialidades e instituciones preocupadas por el buen hablar. A diferencia de la lengua establecida, la del pueblo es un torbellino, un pánico especular, un sistema metaestable. Curiosamente, el término "Estado" deriva de la raíz std-, que incluye, ente otros significados, los de "pararse", "detener", "establecer", “destinar", etcétera (Roberts y Pastor, 1997:168).

Hardt y Negri (2000) utilizan de un modo parecido la noción de "multitud". Frente al Pueblo, ese producto ideológico moderno defendido por Hobbes y que debía encajar como en un guante en el uniformizador Estado-Nación moderno, la "multitud" que Spinoza defendió para reflejar la dinamicidad y creencia de la Holanda del XVII era -dicen Hardt y Negri- "una multiplicidad,

Mairena (heterónimo de Antonio Machado) sobre el pueblo y las menos leídas de José Bergamín (2000:23-57) sobre el analfabetismo. De todas formas, desde el Arcipreste de Hita a Umbral, Delibes o Sastre, pasando por Cervantes, Quevedo, Baroja, Cela, etcétera, hay muchas más reflexiones y figuraciones. Toda esa rica tradición merecería una visita de la sociología. 


\section{Más allá de la sociología}

un plano de singularidades, un juego abierto de relaciones que no es homogéneo ni idéntico a sí mismo". Dicho de otro modo, "mientras la multitud es una relación instituyente inconclusa, el Pueblo es una síntesis constituida que ya está preparada para la soberanía”. Sobra añadir que en la polémica ganó Hobbes y que desde entonces el término "multitud" pasó a tener connotaciones igual de negativas que la "canalla" o la "plebe" en otro tiempo.

Aunque los teóricos impolíticos (como Nancy) o García Calvo y la política radical de Hardt y Negri parecen tener bastante en común, en realidad hay una gran diferencia entre ambos. Mientras los primeros no cesan de quitar significados de toda clase (incluso políticos) al pueblo, la gente o la comunidad, los segundos (aunque con más respeto que los marxistas de otro tiempo) no cesan de introducírselos a la multitud. Allá donde unos ven heterogeneidad y diseminación, los otros perciben potencia revolucionaria. Y si para los primeros tanto el conocimiento como la acción política son imposibles, para los segundos siempre hay algo que se puede hacer. En mi opinión es más consistente y acertada la opinión del primer bando. ${ }^{10}$

\section{Variaciones sobre lo real}

Una característica que tienen en común la comunidad, el pueblo (o la gente) y la multitud es que no acaban de pertenecer a la sociedad,

${ }^{10}$ Fiske (1989:159-194) ocupa una posición intermedia. Opina que es posible una política para el pueblo pero también entiende que la política en general, y la de izquierda en particular, tiene serias limitaciones para entender a la gente. Primero, porque la izquierda siempre le ha adjudicado capacidad para protagonizar cambios revolucionaros, cuando la cultura popular es más bien "progresiva". Segundo, porque la política siempre se ha interesado por los niveles de realidad macro, cuando la cultura popular actúa a un nivel micro. En tercer lugar, porque la política ha sido incapaz de elaborar una teoría sobre el placer popular, a menudo vinculado a la sociedad de consumo. En cuarto lugar, porque la política tampoco le ha dado mucha cabida a las evasiones y resistencias que la cultura popular impulsa en la vida cotidiana. 


\section{Culturales}

ese mundo que solidariamente construyen las élites políticas (junto con las profesionales) y científicas. En efecto, si en algo se parecen todas esas nociones según las retratan Nancy, Espósito, García Calvo, Negri, etcétera, es en el hecho de que tienden a refractar tanto la reflexión científica como las intervenciones políticas y profesionales. Y es que, como "sólo podemos describir y explicar el fracaso justamente con aquellos conceptos que hemos utilizado para construir las estructuras fracasadas, eso jamás puede transmitirnos una imagen del mundo al que pudiéramos hacer responsable del fracaso". Esto dice Von Glasersfeld (Watzlawick, 1995:74-75), uno de los más insignes representantes del constructivismo.

Hemos llegado al lugar falto de esencialismos que nos sugería Nancy, pero comprobamos que es un lugar política y científicamente incómodo ya que no permite hacer ni pensar nada. ${ }^{11} \mathrm{Sin}$ embargo, es justamente en ese lugar donde comparece lo real, la realidad. En efecto, según Heidegger (1993:230-231), la realidad "es resistencia, o más exactamente, condición de resistente". Quiere esto decir que la comunidad es lo que resiste a la sociedad. Es lo que insiste pero sin adquirir nunca consistencia. En el psicoanálisis lacaniano, el registro de lo real (distinto del simbólico

${ }^{11}$ Badiou (1990:52 y ss) no opina así porque interpreta la política de un modo poco convencional. En efecto, la política es para él una "intervención" que propaga los "acontecimientos" más allá de sus situaciones originales. La "intervención" debe entenderse como el conjunto de enunciados y hechos que interpretan el acontecimiento. Y el "acontecimiento" es lo que pasa de lo social instituyente (la comunidad según la estamos interpretando) a lo social instituido (o sociedad) haciendo cortocircuitar este segundo nivel. Dicho de otro modo, "el acontecimiento, por su poder de interrupción, remite a suponer que lo admisible ha dejado de valer" (1990:76). Pues bien, "lo inadmisible es el referente principal de una política digna de ese nombre". En efecto, como un acontecimiento es algo absolutamente a-normal (no está incluido en la estructura de representaciones de la sociedad), lo que trae consigo es no sólo un vacío (respecto a la sociedad) sino una fundación (relativa a la comunidad). De nuevo Badiou: "sólo desde la perspectiva del acontecimiento y de la intervención se puede hacer justicia al exceso del ser" (1999:317). (Nota: en este texto se interpreta el No Ser en el mismo sentido en que Badiou habla del Ser.) 
y del imaginario) es interpretado de un modo muy parecido. En uno de sus seminarios, el psicoanalista francés dice: "hablo de lo real como imposible en la medida en que creo que lo real es sin ley" (Lacan, 2006:135). Zizek (2005:156), buen conocedor de la obra lacaniana, utiliza el filme Matrix ${ }^{12}$ para explicarlo mejor: lo real "no es la verdadera realidad" (es decir, la que pudiera estar "detrás de la simulación virtual" -y, por lo tanto, resultara más verdadera y consistente que la aparente-), sino "el hueco" que hace a la realidad (cualquier realidad -la que está instituida y las que, en otro espacio-tiempo, puedan ocupar su trono-) tener un carácter "incompleto/incoherente". Precisamente, la función de Matrix es ocultar esa incompletitud, incoherencia o falta de ley. ${ }^{13}$ De la sociedad podría hablarse del mismo modo: una de sus misiones fundacionales es ocultar los cortocircuitos que la comunidad (inoperante) no cesa de provocar.

\section{Plus-de-goce, plusvalía y apropiación}

Una vez mostrado que la comunidad no es y que tiene un carácter real, refractario y sustractivo respecto a la sociedad $\mathrm{u}$ orden instituido, hay que ver las relaciones que el "no ser" tiene con el "ser". Para ello nada mejor que inspirarse en un tipo de reflexión, el psicoanálisis, que ha puesto en el centro de su indagación otro "no ser", el in-consciente, así como las relaciones que tiene con su respectivo "ser", la conciencia.

Un interesante concepto acuñado por Lacan para mostrar la compleja relación entre el ser y el no ser es el plus-de-goce.

${ }^{12}$ Más lecturas y usos de Matrix pueden verse en Badiou et al. (2003).

${ }^{13}$ Hardt y Negri (2004:170-171) dicen de ese fondo de indefinición que tiene un carácter demoniaco. Recordando la conversación con un endemoniado que protagoniza Jesucristo (cuando éste pregunta "¿Quién eres?" y aquél le contesta "mi nombre es legión porque somos muchos"), sugieren que "la confusión entre el sujeto singular y el plural es en sí misma un atributo demoníaco" pues "destruye la propia distinción numérica". Del mismo modo, "el número definido de la multitud amenaza todos los principios de orden. Tales artimañas son obras del diablo". 


\section{Culturales}

Para empezar, el goce lacaniano no tiene nada que ver con el significado que se le suele reconocer al término y que es sinónimo de "placer". Para el psicoanálisis lacaniano significa algo bien distinto. Tiene que ver con algo que Freud descubrió en 1920, la pulsión de muerte (Freud, 1993:272-333). En la "compulsión de repetición" de situaciones desagradables que ejecutan los neuróticos en la transferencia y algunos niños con sus juegos - por ejemplo, el de desaparición ("fuera”) y reaparición ("aquí") con el que uno de los nietos de Freud representaba las desapariciones y reapariciones de su madre-, aunque en principio sirve al sujeto para dominar una violenta impresión, también tiene que ver con la insistencia de algo implícito al símbolo. Freud dijo de esa insistencia que tiene que ver con "una tendencia de lo orgánico vivo a la reconstrucción de un estado anterior". Dicho de otro modo, la vida no sería sino un rodeo forzado por las derivas de la evolución que la muerte intentaría amortiguar. Por lo tanto, la muerte es una pulsión que lleva a regresar a lo preconstituido, la base informe sobre la que se asienta el orden. Creo que de la comunidad (gente o multitud) podría hablarse del mismo modo, pues también ella es el fondo inmanente en el que inexorablemente terminan diluyéndose todas las Sociedades.

$\mathrm{Si}$ el goce tiene que ver con el exceso (respecto a lo instituido y lo soportable) al que conduce la pulsión de muerte, el plus-degoce hace referencia a cierta relación que llega a establecerse entre el orden y su inconmensurable afuera. Dicha relación tiene que ver con el hecho de que el deseo (proveniente precisamente de la escisión o separación entre lo instituido y su exterior), a pesar de estar re-presentado (vuelto a presentar -es decir, suplantado, ausentado...-) por las cadenas de signos que sostienen al sujeto y su Sociedad, extrae cierto plus de placer cada vez que el sujeto se encarna en tales signos (Lacan, 1992:47-54). Lo que sucede entonces es que el afuera es desactivado al anudarse al orden instituido y proporciona a partir de ese momento un plus de goce propio del nudo. Por lo tanto, si el goce cae 


\section{Más allá de la sociología}

del lado de lo Otro, lo absolutamente diferente a lo instituido (que es la sociedad para los sociólogos, la conciencia para los psicólogos), el plus de goce es la bisagra, membrana o frontera que articula uno y otro mundo. Si con el goce estamos ante un "no ser" absoluto, inconmensurable, excluido desde los propios orígenes y fundamentos del orden, con el plus de goce la exterioridad ha sido igualmente excluida pero por el procedimiento de la inclusión.

Lo curioso es que, si bien Lacan inspiró sus análisis sobre el plus-de-goce a partir de los análisis de Marx sobre la plusvalía, ambas reflexiones eran radicalmente distintas pues partían de sensibilidades y puntos de vista diferentes. En efecto, el plus-de-goce implica un retorno de lo apartado que, desde el punto de vista lacaniano, comprometido como está con el orden subjetivo instituido, resulta insoportable. ${ }^{14}$ En cambio, Marx partió de un afuera, representado por el trabajo, que podía redimir el orden que el capital había instituido. De ahí que la aparición del trabajo en la plusvalía evocara sensaciones distintas.

La confrontación no es menor, pues, cuando lacanianos y marxistas han visitado los campos de análisis que sus contrarios han llevado consigo el mismo tipo de análisis. Por eso los lacaniannos han solido calificar de ilusoria la posibilidad de liberación que impulsan los marxistas. ${ }^{15}$ Y por eso los marxistas han cuestionado

${ }^{14}$ La psicología transpersonal (Wilber, 1995:95-97) lo ve de otro modo. En su opinión, ese fondo de indistinción al que atrae la pulsión de muerte cumple la función de permitir deshacer el orden instituido y facilitar así la emergencia de nuevas estructuras. Esta función de la pulsión de muerte es muy parecida a la que cumple Shiva, el dios más venerado del hinduismo. El esquizoanálisis de Deleuze y Guattari (1985:332 y s) interpreta del mismo modo la pulsión de muerte cuando apuesta por el "cuerpo sin órganos", plano de inmanencia caracterizado por la libre circulación de flujos y que tiende a refractar la organización, la significación y la subjetivación.

${ }^{15}$ Esto es algo que se puede comprobar en una sesión de los seminarios de Lacan que tuvo lugar el 3 de diciembre de 1969. Acudieron a ella unos cuantos revoltosos sesentayochistas que pusieron en jaque a Lacan y mos- 


\section{Culturales}

el carácter necesario e inevitable que los lacanianos otorgan a la represión. ${ }^{16}$

En mi opinión, lacanianos y marxistas muestran puntos de vista absolutamente contrarios respecto a un fenómeno que no sólo es formalmente idéntico, ya que, en el fondo, ambos hablan de las relaciones entre lo instituido y lo instituyente que se dan tanto en la subjetividad como en lo social. Pues bien, si damos por válidas ambas interpretaciones deberíamos concluir que la relación entre lo instituido y lo instituyente (entre la sociedad y la comunidad, la conciencia y el inconsciente) es paradójica. Lo es porque, como recuerda Purroy Chicot (1997), una paradoja está formada por lados que se complementan de un modo contradictorio. Tal es el lugar al que inexorablemente llevan los sistemas jerárquicos cualquiera que sea su clase.

Este carácter paradójico del vínculo entre lo instituido y lo instituyente puede verse mejor en la noción de apropiación de Lefebvre (1984:111), que tan útil ha resultado en sociología urbana y en el análisis del carácter activo que tiene la recepción de los productos mediáticos. Según el sociólogo bearnés, la apropiación "aprehende las coacciones, las transforma y las cambia en obras". De modo que, si hacemos caso literalmente a la definición, los mismos instrumentos utilizados por la sociedad para construir cierto orden son reutilizados por la comunidad para escapar de dicho orden y dar lugar a algo nuevo. Un magnífico ejemplo de apropiación lo proporcionó Michel de Certeau (1990:XXXVII-XXXVIII):

Hace tiempo que se viene estudiando el equívoco que cuarteaba por dentro el "triunfo" de los colonizadores españoles con respecto a las

traron la enorme diferencia que separa a psicoanalistas y revolucionarios (Lacan, 1992:211-223).

${ }^{16} \mathrm{El}$ primer autor que lo hizo fue Wilheim Reich, al denunciar que Freud descubrió una represión inconsciente que con su psicoanálisis transformó en una reprobación y renuncia conscientes (Reich, 1985:40). De ahí su propuesta de eliminar de la terapia la atención a los impulsos secundarios o "antisociales" (basados en la "coerción moral") para dar paso a una "autorregulación sexual" (1985:51). 


\section{Más allá de la sociología}

colonias autóctonas: con frecuencia esos indios insumisos, e incluso consintientes, hacían con las liturgias, las representaciones o las leyes que se les imponían otra cosa distinta de lo que el conquistador creía conseguir a través de ellas; las subvertían, no rechazándolas o cambiándolas, sino utilizándolas de una manera, con unas finalidades y en función de unas referencias extrañas al sistema del que no podían escapar. Eran distintos desde lo más profundo del orden que los asimilaba exteriormente; esos indios se le iban de la mano al conquistador pero sin abandonarlo.

La cita es interesante, entre otras cosas, porque pone en un primer plano el carácter paradójico que tiene el pueblo, ya que no se puede decidir en qué medida lo que se denomina "cultura popular", uno de sus atributos, es producto de las relaciones de dominación o de la potencial autonomía que la gente activa a través de la apropiación (O’Sullivan, Hartley, Saunders, Montgomery y Fiske, 1997:232). Dice Fiske (1992:157) que las dos lecturas son posibles: "el orden social constriñe y oprime al pueblo pero, al mismo tiempo, le ofrece recursos para luchar contra las instituciones". Si esto es así, la opresión y la apropiación sólo son nombres distintos dados a un mismo fenómeno.

Hemos llegado a un escenario en el que el orden instituido no sólo ha excluido su afuera. Al excluirlo vía inclusión, ha inventado un mundo paradójico en el que la demagogia, el cinismo, la artimaña, el engaño y otras sociabilidades paradójicas ocupan un lugar central. Aunque habrá quien diga que el mundo tal cual lo tenemos no da para algo distinto, otros opinarán que hay muchos más mundos. Uno de ellos puede hacerse aparecer simplemente reflexionando sobre si los dos lados de lo social, además de relaciones dialécticas que inevitablemente desembocan en síntesis paradójicas, son capaces de entablar vínculos de otro tipo. Vínculos que no tengan que ver con imposiciones (que oscilan entre el despotismo y el paternalismo) a las que inevitablemente suceden resistencias (que oscilan entre la confrontación y la apropiación). 


\section{Culturales}

\section{Más allá de las paradojas}

La Autonomous Network Theory (ANT) (Espósito, 2005:38-51; Capra, 1998:87-291), al reflexionar sobre los procesos de inmunización, ha dado a entender que ese otro mundo es posible. Este ámbito de reflexión es pertinente para ver las relaciones de la comunidad con la sociedad pues, etimológicamente, "inmune" es lo que interrumpe el munus y, en consecuencia, se opone a la comunidad. Por eso los antiguos llamaban "inmunes" a los ingratos y calificaban como "muníficos" a los agradecidos y generosos. Por otro lado, la referencia a la inmunología es necesaria porque la interpretación clásica trabajaba con una paradoja muy similar a la que se da entre la sociedad instituida y la comunidad (pueblo, gente o multitud) instituyente. Según esa interpretación, es necesario administrar homeopáticamente lo otro para que el sistema se proteja mejor contra ello.

La nueva inmunología ha deshecho la paradoja tras demostrar que los anticuerpos enlazan con todo tipo de células, no sólo con "sus" antígenos. También ha mostrado que los enlaces no tienen como finalidad la destrucción del Otro. Finalmente, la persistente tolerancia de los anticuerpos frente a los antígenos invasores ha obligado a abandonar las metáforas bélicas. Para aceptar estas conclusiones, los nuevos analistas de la ANT han terminado concluyendo que los antígenos y anticuerpos son elementos de una misma red que, de manera alternada o también simultánea, desempeñan uno u otro papel. Obsérvese que para esta explicación desaparece el afuera, lo Otro. El cuerpo, "antes que como barrera de selección y exclusión respecto de lo externo, funciona como caja de resonancia de su presencia en el interior del yo" (Espósito, 2005:240). Así que "el equilibrio del sistema inmunitario no es el fruto de una movilización defensiva contra lo otro sino el punto de convergencia de series diferentes" (2005:247). Esta constatación de que lo exterior y negativo es también interior y positivo lleva a cuestionarse 


\section{Más allá de la sociología}

la pertinencia de distinciones tales como interior/exterior, positivo/negativo, etcétera. ${ }^{17}$

Con la ANT no sólo desaparece la diferencia anticuerpo/ antígeno. También han comprobado sus investigadores que la distinción entre los sistemas inmune, endocrino y nervioso no es muy consistente, pues hay una familia de entre 60 y 70 macromoléculas, los péptidos, que relacionan los anticuerpos, los órganos y el cerebro dando lugar a un conjunto psicosomático en el que la distinción de partes o subconjuntos deja de ser pertinente.

En definitiva, la nueva inmunología ha dejado de lado la mirada que sólo sabe ver diferencias y trabajar con distinciones para empezar a tomarse en serio las conexiones. Como consecuencia de esta nueva mirada desaparecen las jerarquías y emergen las totalidades. Esta nueva mirada está exigiendo una praxis terapéutica que la medicina convencional aún no puede proporcionar.

En mi opinión, en el ámbito de lo social es necesario abrir la puerta a una reflexión similar. Se encargaría de dejar de lado la distinción comunidad/sociedad, así como sus vínculos paradójicos, para pasar a ver lo social (es decir, todo) en su

${ }^{17}$ La microbiología ha observado un fenómeno parecido investigando el ADN de las bacterias. Gracias a unas partículas genéticas llamadas "replicones" que las visitan aportando material genético, pueden llegar a recibir un 50 por ciento de genes nuevos sin alterarse. "Si se aplicaran las propiedades genéticas del microcosmos a criaturas de mayor tamaño, nos encontraríamos en un mundo de ciencia ficción en el que las personas podrían exudar perfumes o producir marfil consiguiendo los genes a partir de una rosa o un elefante" (Margulis y Sagan, 1995:104-105). Esta propensión a la mezcla e hibridación (más poderosas que las lógicas de la distinción y de la competencia) está también presente en un fenómeno ciertamente singular al que Margulis ha puesto el nombre de "simbiogénesis". Por ejemplo, en las células con núcleo, básicas para cualquier forma de vida, las "mitocondrias" fueron originalmente bacterias que acabaron ocultándose en el interior de células bacterianas mayores. Allí obtuvieron nutrientes, y a los huéspedes les vino bien que consumieran oxígeno, pues éste resultaba nocivo para su ADN (pp. 143-149). 


\section{Culturales}

conjunto. La sociología no puede practicar esta otra mirada porque sólo sabe trabajar con distinciones y jerarquías. En efecto, el logos (como dijo Descartes) sólo debe ver cosas claras y distintas. ${ }^{18}$ Por su parte, la ciencia, que deriva de la raíz indoeuropea -skei, que significa "cortar", "separar", tampoco sabe tratar con totalidades.

\section{Por una sociosofía}

Para practicar una reflexión no sociológica sobre lo social hay, en primer lugar, que tomar nota del mundo que queremos pensar. Se trata de un mundo en el que las partes (no sólo la comunidad y la sociedad) no están separadas por distinciones jerárquicas sino relacionadas por conjunciones. Por ejemplo, en lugar de esa separación entre individuos que instituyó la Modernidad, interesa lo que une, el "entre" o el "con" (el ser-uno-con-otro) que media entre los individuos (Nancy, 2006a:21-23). El mismo gesto (de apostar por la conjunción en lugar de hacerlo por la distinción) podría realizarse con relación a los grupos, las (sub)culturas, etcétera, pues todas esas "realidades" han sido creadas a partir de actos de distinción que han separado a unos grupos, (sub)culturas y situaciones de otros.

El vínculo o "con” del que hablamos no tiene mucha consistencia física. Es simplemente una disposición del sujeto a disolverse en la interioridad del socius. Dice Simondon (1989:191-194), a propósito de esto, que cada sujeto lleva consigo ese fondo preindividual y que se activa cuando contacta con otros. Esta realidad que emerge "entre" o "con" tiene, pues, un carácter transindividual. Se diferencia de lo interindividual en que no pone en conexión a los seres individuados sino que los atraviesa. También implica que, en lugar de comunicación, provoca la resonancia y sinergia entre los sujetos. Sloterdijk (2003:226-227 y 343-349) ha situado el estímulo psíquico de ese "ser-con", no en el Edipo,

${ }^{18}$ Véase Serres (1991:41 y ss). 


\section{Más allá de la sociología}

origen de todas las distinciones (así como de su subproducto lógico, la paradoja), ${ }^{19}$ sino en la relación del todavía-no-nacido con la placenta. ${ }^{20}$

Dice Sloterdijk que ese vínculo preedípico y preindividual obliga a hablar de lo social en términos de "ambiente", "atmósfera" o "clima", pues los sujetos, al tender a recrear los vínculos amnióticos y placentarios, generan inevitablemente realidades gaseosas (Sloterdijk, 2004:131-132) que evocan la calidez del útero (2004:178). Por lo tanto, si cierta sociología habla de líquidos y fluidos que habrían disuelto las estructuras físicas de otro tiempo, también es posible prestar atención a la evaporación de los fluidos y a la sublimación de los sólidos. ${ }^{21} \mathrm{De}$ todas formas, la importancia del contexto gaseoso no es nueva. Ya la supo ver Aristóteles cuando habló de un quinto elemento (además de la tierra, el fuego, el aire y el agua), o quintaesen-

${ }^{19}$ Deleuze y Guattari (1985:85) lo han expresado mucho mejor: Edipo "obliga al deseo a tomar por objeto las personas parentales diferenciadas y prohíbe al yo correlativo que satisfaga su deseo con esas personas, en nombre de las mismas exigencias de diferenciación, esgrimiendo las amenazas de lo indiferenciado" (es decir, la castración). La autoridad terminará salvando al sujeto de la trampa edípica. Frente a un psicoanálisis que no sabe ni quiere ver más allá de Edipo, Deleuze y Guattari proponen el esquizoanálisis, cuya inspiración viene del mundo que trae consigo y no puede terminar de realizar el esquizofrénico. En ese mundo no hay carencias o faltas sino producción incesante. Y en lugar de papá y mamá está el mundo con toda su diversidad (véase pp. 395 y ss).

${ }^{20}$ Con relación a esto, conviene dejar constancia de que el individuo moderno surgió al tiempo que la placenta terminó en la basura (Sloterdijk, 2003:350). Sin embargo, más tarde, primero las industrias cosméticas y después las investigaciones médicas no han cesado de experimentar con ellas. Esto ha sucedido a la par que cierta sociología disolvía al individuo en su humus. De modo que el orden actual parece querer desanclar y reanclar una dimensión de lo social que en los orígenes de la Modernidad no mereció mucha estima.

${ }^{21}$ Con Concha Martínez, Miguel Montañés, Pilar Negrete y Teresa Martínez, hemos querido analizar la creatividad en el ámbito de la moda prestando atención a las atmósferas estéticas que diseñadores y tribus, cada uno de distinto modo, crean y transpiran (Bergua et al., 2007). 


\section{Culturales}

cia, que llamó “éter". Los poetas antiguos, menos prosaicos, habían utilizado ese mismo término para designar la sustancia sutil que llena el cielo y que "corre constantemente (aeítheí) en un tiempo eterno" (2004:347). También se refirieron a ese sustrato utilizando otra noción, la de pneuma (espíritu), que en el cristianismo, a pesar de lo difícil que resultó hacerle un hueco, ocupó un lugar fundamental. En la actualidad, Sloterdijk ha sugerido recuperar ese modo de ver y estar en el mundo con su "esferología".22

A finales del siglo diecinueve Eliphas Levi acuñó el término "ocultismo" para referirse a la reflexión que exigen los climas, ambientes y atmósferas relacionados con la presencia del éter y del pneuma. Según este punto de vista, "todo objeto pertenece a un conjunto único y posee con todos y cada uno de los elementos de dicho conjunto relaciones necesarias, intencionales, no temporales y no espaciales" (Amadou, 2003:47). El ocultismo se ocupa, entonces, de los vínculos o correspondencias que ponen en relación todo. La relación concreta que vincula las cosas es la analogía.

Otra interesante sugerencia de los saberes ocultos es que no disocian la reflexión de la acción. Así lo expresó Giordano Bruno (2000) al referirse a la magia:23 "el mago designa a un hombre que alía el saber al poder de obrar". Por lo tanto, no

${ }^{22}$ Sloterdijk (2004:187) añade que los dioses también tienen que ver con ese amnios. Simondon (1989:105) concluye algo parecido cuando asegura que "la espiritualidad es el acto por el que el individuo recupera su preindividualidad a través de lo colectivo".

${ }_{23}$ "Mago ha significado en primer lugar sabio: lo eran los trimegistos en Egipto, los druidas en la Galia, los gimnosofistas en India, los cabalistas entre los hebreos, los magos en Persia (desde Zoroastro)..." (Bruno, 2000:7). Al parecer, los sabios griegos aplicaron en lo social un saber-hacer de carácter mágico u ocultista que algunos autores han preferido aplicarle el calificativo de "chamánico" (Vernant, 1992:21; Dods, 1986:138 y ss; Culiano, 1993:136 y ss, y 1994:31 y ss). Dicho saber-hacer solucionaba los problemas sociales a través de distintas clases de rituales que provocaban la anamnesis de sus causas originales. Tales causas no eran políticas sino espirituales. 
estamos ante la distinción entre élites científicas y políticas que prevalece en el mundo de las distinciones y jerarquías. Lo interesante es que esta relación entre el saber y el hacer es también la que nos encontramos en las multitudes, gentes o comunidades, pues en su vida cotidiana utilizan una "razón común" que se caracteriza (además de por ser común -no personal-) por tener un carácter práctico y situado. Lo que diferenciaría al mago de la gente es que ésta practica su saberhacer de un modo automático y subconsciente, mientras que aquél es perfectamente consciente.

Hoy sabemos que los científicos (tanto duros como blandos) suelen sacar adelante su trabajo reflexivo dejándose guiar más por su razón común que por las reglas y métodos de la ciencia. Quizás con los políticos y profesionales (con sus protocolos de actuación) suceda algo parecido. ${ }^{24}$ Por lo tanto, la ciencia, la política y la profesionalidad se diferencian del ocultismo o la magia en que las primeras o son ignorantes (porque no saben que usan un saber práctico) o cínicas (pues hacen como que no lo saben), mientras que las segundas explicitan la relación entre el saber, el hacer y el contexto.

Otra importante característica de la sociosofía es que, como el ocultismo y la magia, se ocupa de lo oculto. Es decir, del "no ser", de sus vínculos analógicos con el ser y del éter o

${ }^{24}$ Con relación al uso del "saber común" según lo utiliza la sociología, véase Watier (2000:91 y ss). En cuanto a la permanente presencia del "conocimiento tácito" en la ciencia, véase Feyerabend (1999:81, 128 y 161). La expresión "razón común", que en mi opinión engloba las dos anteriores, es de García Calvo. Dice el zamorano que está ya presente en algunos fragmentos de Heráclito, que él mismo se encarga de traducir y comentar. Heráclito: "común a todos es el pensar" (113 D-K) y "razonando deben hacerse fuertes en lo común de todos" (114 D-K), "pero siendo la razón común, viven los más como teniendo un pensamiento privado suyo" (2 D-K). Comentarios de García Calvo: "la contradicción de que, siendo la razón común a todos..., los hombres no tengan conciencia de lo que hacen y se muestren extraños a la razón, consiste precisamente en que cada uno cree que su inteligencia, lo que dice y las ideas que se le ocurren son propias y personales" (García Calvo, 1985:37-43). 


\section{Culturales}

espíritu que facilita la vinculabilidad entre todo. Pues bien, para ser coherente con ese mundo oculto, la sociosofía, como sucede con los saberes esotéricos, debe permanecer también oculta. Esto quiere decir que no debe divulgarse y enseñarse como la ciencia. ${ }^{25}$ Debe utilizar otros medios de transmisión. Por ejemplo, la conversación y la ejemplaridad. Así, al menos, enseñaba el indio Don Juan a Carlos Castaneda. ${ }^{26}$ Otro recurso es la parábola. ${ }^{27}$

${ }^{25}$ Por eso difiero de Santos (2005:160). Estoy de acuerdo en que "lo que no existe es producido como no existente... (y que) su objetivo empírico es imposible a la luz de las ciencias sociales convencionales por lo que su simple formulación representa ya una ruptura con ellas". En lo que no estoy de acuerdo es en la sugerencia de que una "sociología de las ausencias", combinada con una "sociología de las emergencias", podría recuperar lo imposible. No lo estoy porque las ciencias sociales, por más flexibles que sean, nacieron en un orden basado en dominaciones y exclusiones, por lo que, si bien pueden detectar lo inexistente, no pueden ni podrán saber nada de él. El orden, llevado por la autocrítica (a su vez estimulada por un sentimiento de mala conciencia), sólo puede reconocer que no sabe (científicamente) y que nada puede hacer (políticamente) con aquello que ha decidido que no sea. La sociología de las ausencias sólo puede registrar esas ausencias, interpretar las exclusiones y analizar los rastros o las huellas que han quedado de lo excluido. Nada más. La "sociología de las emergencias" (pp. 167-171) presume que en lo excluido anida la posibilidad de aparición de algo nuevo. Aunque esta presunción está justificada, es imposible saber y hacer nada con esa potencia o posibilidad porque el saber y el hacer provienen los dos de lo instituido. La imposibilidad de lo excluido obliga a dejar de lado instrumentos utilizados por el orden como son la ciencia y la política.

${ }^{26}$ Véase, por ejemplo, el que en mi opinión es el mejor volumen de las enseñanzas de Don Juan (Viaje a Ixtlán, Fondo de Cultura Económica).

${ }^{27}$ Dice Nancy (2006b:12-14) que las parábolas de Jesucristo no tienen como misión aclarar la visión y el entendimiento. No proceden de una pedagogía de la ilustración, sino, muy al contrario, de "un rechazo o una negación de toda pedagogía". Y es que es necesario tener ya una disposición receptiva para recibir, que no tiene que ver con ningún misterio religioso, sino que es la condición misma de la receptividad, de la sensibilidad y del sentido en general: "las palabras divino y sagrado podrían perfectamente no haber designado nunca otra cosa que esa pasividad o esa pasión iniciadora en los sentidos, 
Otra característica que la sociosofía podría copiar de los saberes esotéricos es el tender permanentemente puentes hacia los saberes exotéricos, como la filosofía y la ciencia. El problema es que estos otros saberes no han cesado de repudiar el contacto con los primeros. Aún así, hay destacados pensadores que, si bien la ciencia y la filosofía ha considerado como propios, en realidad cultivaban también el conocimiento de lo oculto. Es el caso, por ejemplo, de Giordano Bruno, aclamado como un librepensador que murió en la hoguera pero que -esto no se subraya lo suficiente- fue también mago. Es igualmente el caso de Newton. En efecto, según Prigogine y Stengers (1990:93-95), la noción de fuerza ("que permitía dar una formulación común a fenómenos que en principio no tenían ninguna elación entre sî") fue el resultado de treinta años de estudio y exploración alquímica, paralelos a sus estudios matemáticos. De modo que Newton unió el saber superior de la matemática con el oculto de la alquimia. Sin embargo, la historia oficial de la ciencia nunca ha prestado mucha atención a este vínculo. Ha preferido ocultarlo y mantener así la superioridad de la ciencia y la invisibilidad de los otros saberes. ${ }^{28}$

Finalmente, más allá de lo que la sociosofía pueda tomar o copiar de los saberes ocultos, debe tener como característica propia el ocuparse de lo social, que es todo. No tiene que ver con la sociedad (u orden instituido) ni con la comunidad (producida como exterioridad por la autoinstitución de la sociedad, después incorporada imaginariamente y finalmente realizada como simulacro ${ }^{29} \mathrm{ni}$ con las relaciones paradójicas entre ambas partes.

lo sensitivo o lo sensual". Pues bien, la parábola cumple la función - parafraseando a San Mateo- de dar al que ya cultiva esa disposición (pues entenderá) y de quitársela a quien no la ejercita (pues no podrá comprender nada).

${ }^{28}$ Por cierto, tampoco ha prestado ninguna atención al hecho de que un gran e influyente científico del siglo veinte, Keynes, pagara una gran cantidad de dinero en una subasta por los manuscritos alquímicos de Newton.

${ }^{29}$ En parte, ésta es la tesis de Barcellona (1996). El nacimiento del Estado moderno, al tiempo que acabó con los vínculos de servidumbre, 


\section{Culturales}

Lo social tiene ver con el todo que convierte en inapropiados todos esos términos. ${ }^{30}$

\section{Bibliografía}

Amadou, R., El ocultismo. Las doctrinas, las prácticas y la religión de lo oculto, Alamah, México, 2003.

B Adiou, A., ¿Es posible la política?, Nueva Visión, Buenos Aires, 1990.

— Ser y acontecimiento, Manantial, Buenos Aires, 1999.

Badiou, A., Th. Benatoull, E. During, P. Maniglier, D. Rabouin y J.-P. Zarader, Matrix. Machine Philosophique, Ellipses, París, 2003.

Barcellona, P., Postmodernidad y comunidad, Trotta, Madrid, 1996.

Bataille, G., El Estado y el problema del fascismo, Pre-textos, Valencia, 1993.

BЕск, U., "La irresponsabilidad organizada", Debats, 35/46, pp. 30-37, 1991.

__, "De la sociedad industrial a la sociedad del riesgo. Cuestiones de supervivencia, estructura social e ilustración ecológica", Revista de Occidente, 150, pp. 19-40, 1993.

Benasayag, M., y A. Del Rey, Éloge du conflit, La Découverte, París, 2007.

Bergamín, J., La importancia del demonio, Siruela, Madrid, 2000.

Bergua, J. A., La gente contra la sociedad. Impacto sociocultural de un divertimento juvenil, Mira, Zaragoza, 2002.

_- Lo social instituyente. Materiales para una sociología no

eliminó también las relaciones basadas en la cooperación orgánica. En su lugar prometió y construyó una comunidad de ciudadanos, formada por individuos libres e independientes, que nunca ha dado la talla. En el paisaje de simulacros que han realizado esa promesa debe incluirse el comunismo.

${ }^{30}$ Con relación a la sociosofía, puede verse Bergua, 2007:81-84, 22-127, $58-163,194-197$ y $229-232$. 
clásica, Prensas Universitarias de Zaragoza, Zaragoza, 2007. Bergua, J. A., et al., Coolhunting. Diseñadores y multitudes estéticas en Aragón, Diputación General de Aragón, Zaragoza, 2007.

Bruno, G., De la magie, Editios Allia, París, 2003.

$\mathrm{C}_{\mathrm{APRA}}$, F., La trama de la vida. Una nueva perspectiva de los sistemas vivos, Anagrama, Barcelona, 1998.

Carretero Pasín, E., Pouvoir et imaginaires sociaux. La légitimation de l'ordre social dans les societés postmodernes, L'Harmattan, París, 2006.

Certeau, M. DE, L'invention du quotidien, 1. Arts de faire, Gallimard, París, 1990.

Clastres, P., La societé contre l'État, Minuit, París, 1974.

Couliano, I. P., Más allá de este mundo. Paraísos, purgatorios e infiernos: un viaje a través de las culturas religiosas, Paidós, Barcelona, 1993.

—, Experiencias del éxtasis, Paidós, Barcelona,: 1994.

Deleuze, G., y F. Guattari, El Anti-Edipo. Capitalismo y esquizofrenia, Paidós, Barcelona, 1985.

_- Mil mesetas. Esquizofrenia y capitalismo, Pre-Textos, Valencia, 1988.

Dods, Los griegos y lo irracional, Alianza, Madrid, 1986.

Dupuy, J.-P., Pour un catastrophisme éclairé. Quand l'impossible est certain, Seuil, París, 2002.

Espósito, R., Comunitas. Origen y destino de la comunidad, Amorrortu, Buenos Aires, 2003.

—- Inmunitas. Protección y negación de la vida, Amorrortu, Buenos Aires, 2005.

Feyerabend, P. K., Ambigüedad y armonía, Paidós, Barcelona, 1999.

Fiske, J., Understanding Popular Culture, Routledge, Londres, 1989.

_ _, "Cultural Studies and the Culture of Everyday Life", en L. Grossberg, C. Nelson y P. Treichler, Cultural Studies, Routledge, Londres, 1992. 


\section{Culturales}

Foucault, M., Genealogía del racismo, Ediciones La Piqueta, Madrid, 1992.

Freud, S., Textos de psicoanálisis, Altaya, Madrid, 1993.

García Calvo, A., Razón común. Edición crítica, ordenación, traducción y comentario de los restos del libro de Heráclito, Lucina, Zamora, 1985.

—, Contra el tiempo, Lucina, Zamora, 1993.

__, "El hombre contra la gente", Cuchará y paso atrá, núm. 7, pp. 65-77, 1999.

GIL Calvo, E., El miedo es el mensaje. Riesgo, incertidumbre y medios de comunicación, Alianza, Madrid, 2003.

Hardt, M., y T. Negri, Empire, Harvard University Press, Cambridge, 2000.

_- Multitud. Guerra y democracia en la era del imperio, Debate, Madrid, 2004.

Heidegger, M., El ser y el tiempo, Planeta-Agostini, Barcelona, 1993.

LaCan, J., El seminario, 17. El reverso del psicoanálisis, Paidós, Barcelona, 1992.

_-, El seminario, 23. El sinthôme, Paidós, Buenos Aires, 2006.

Laclau, E., La razón populista, Fondo de Cultura Económica, Buenos Aires, 2005.

Lamo de Espinosa, E., La sociedad reflexiva, cis, Madrid, 1990.

Lefebvre, H., La vida cotidiana en el mundo moderno, Alianza, Madrid, 1984.

Lourau, René, El estado y el inconsciente, Kairós, Barcelona, 1980.

Margulis, L., y D. SAGan, Microcosmos. Cuatro mil millones de años de evolución desde nuestros ancestros microbianos, Tusquets, Barcelona, 1995.

Maturana, H. R., y F. Varela, De máquinas y seres vivos. Autopoiesis: la autoorganización de lo vivo, Editorial Universitaria, Santiago de Chile, 1995.

Merton, R. K., Teoría social y estructura social, Fondo de Cultura Económica, México, 1987. 
NAncy, J.-L., La comunidad inoperante, Universidad Arcis, Santiago de Chile, 2000.

—_, Ser singular plural, Arena Libros, Madrid, 2006a.

_- Noli me tangere. Ensayo sobre el levantamiento del cuerpo, Trotta, Madrid, 2006b.

Neyrat, F., "Biopolitique des catastrophes", Multitudes, núm. 24, pp. 107-117, 2006.

Orlean, A., "The Origin of Money", en F. Varela y J. P. Dupuy (eds.), Understanding Origins, Kluwer Academic Publishers, Londres, 1992, pp. 113-143.

O’Sullivan, T., J. Hartley, D. Saunders, M. Montgomery y J. Fiske, Key Concepts in Communication and Cultural Studies, Routledge, Londres, 1997.

Poundstone, W., El dilema del prisionero, Alianza, Madrid, 1995.

Prigogne, I., e I. Stengers, La nueva alianza. Metamorfosis de la ciencia, Alianza, Madrid, 1992.

Purroy Chicot, P., "La música como propuesta de otra forma evolucionada de racionalidad", ponencia presentada en la Conferencia Internacional sobre Evolucionismo y Racionalismo, Seminario Interdisciplinar, Zaragoza, 1997 (inédito).

ReIch, W., La revolución sexual, Planeta-Agostini, Barcelona, 1985.

Roberts, E. A., y B. PAstor, Diccionario etimológico indoeuropeo de la lengua castellana, Alianza, Madrid, 1997.

Rosset, C., Lo real. Tratado de la idiotez, Pre-Textos, Valencia, 2004.

SAntos, B. DE S., El milenio huérfano. Ensayos para una nueva cultura política, Trotta, Madrid, 2005.

Serres, M., El paso del noroeste, Debate, Madrid, 1991.

Simondon, G., L'individuationpsychique et collective, Aubier, París, 1989.

Sloterdiuk, P., Esferas I, Siruela, Madrid, 2003.

— Esferas II, Siruela, Madrid, 2004. 


\section{Culturales}

Varios Autores, "Investigación-Acción-Participativa", Documentación Social, 92, 1993 (número monográfico).

Vernant, J. P., Mito y religión en la Grecia antigua, Ariel, Barcelona, 1992.

W Atier, P., Le savoir sociologique, Desclée de Brouwer, París, 2000.

W atzlawick, P., El sinsentido del sentido o el sentido del sinsentido, Herder, Barcelona, 1995.

Wilber, K., Al este del Edén, Kairós, Barcelona, 1995.

Zizen, S., La suspensión de toda ética, Fondo de Cultura Económica, México, 2005.

Fecha de recepción: 11 de noviembre de 2008

Fecha de aceptación: 3 de marzo de 2009 